\title{
PENERAPAN ASUHAN KEPERAWATAN PADA PASIEN DENGAN TUBERKULOSIS PARU DALAM PEMENUHAN KEBUTUHAN KEAMANAN DAN KESELAMATAN DI RUMAH SAKIT TINGKAT II PELAMONIA MAKASSAR
}

Application of nursing care to patients with lung tuberculosis in fulfilling security and safety needs in-room Pelamonia Hospital-level II Makassar

\author{
Nurlina, Hasnah $\mathrm{H}$ \\ Nursing Diploma III Study Program \\ Makassar Muhammadiyah University \\ Email : nurlinajamal@gmail.com \\ HP : 081260674014
}

\begin{abstract}
ABSTRAK
Latar Belakang: Menurut data World Health Organization (WHO) tahun 2018 diperkiraan ada 10,4 juta kasus TB Paru di seluruh dunia, dan 1,7 juta meninggal karena penyakit TB paru, dimana 6,2 juta sejumlah laki-laki 3,2 juta adalah perempuan. Indonesia termasuk dalam tujuh negara yang menyumbang $64 \%$ dari kasus-kasus baru di dunia dan menjadi urutan kedua setelah india dengan penderita TB paru tertinggi di dunia secara global, angka kematian TB paru mengalami penurunan sebesar 37\% antara tahun 2000 dan 2016. Tujuan: Menggambarkan penerapan asuhan keperawatan pada pasien tuberkulosis paru dalam pemenuhan kebutuhan keamanan dan keselamatan. Metode: Studi kasus ini menggunakan rancangan studi kasus deksriptif. Data dari hasil penelitian di sajikan dalam bentuk studi kasus dengan menggunakan pendekatan proses keperawatan. Kesimpulan: berdasarkan hasil penelitian yang telah dilakukan didapatkan pada tn.S adalah masalah Resiko cedera/jatuh berhubungan dengan kelemahan, Resiko penyebaran infeksi berhubungan dengan penurunan system imun, aspek kronis penyakit, Perubahan proteksi berhubungan defisit imunologi. Saran: Saran bagi perawat yang dimana, perawat rumah sakit seharusnya memberikan edukasi atau pemahaman kepada keluarga pasien tentang mudahnya menular penyakit tuberkolosis tersebut, dan meberikan pemahaman tentang bagaimana mencegah agar tidak terjadi penularan ke anggota keluarga lainnya.
\end{abstract}

Kata kunci: Tubercolusis Paru, Asuhan Keperawatan, Kebutuhan Keamanan dan Keselamatan

\section{ABSTRACT}

Background: According to World Health Organization (WHO) data in 2018 there are an estimated 10.4 million cases of pulmonary TB worldwide, and 1.7 million died of pulmonary TB, of which 6.2 million are 3.2 million men is female. Indonesia is among the seven countries that account for $64 \%$ of new cases in the world and ranks second after India with the highest pulmonary TB sufferers in the world globally, the pulmonary TB mortality rate has decreased by $37 \%$ between 2000 and 2016. Objective: To describe the application of nursing care to pulmonary tuberculosis patients in meeting security and safety needs. Method: This case study uses a descriptive case study design. Data from the research results are presented in the form of case studies using the nursing process approach. Conclusion: Based on the results of research that has been done found in th.S is the problem of the risk of injury/fall associated with weakness, the risk of spread of infection associated with a decrease in the immune system, chronic aspects of the disease, changes in protection related to immunological deficits. Suggestions: Suggestions for nurses where, Hospital nurses should provide education or understanding to the patient's family about the ease of transmission of the tuberculosis disease, and provide an understanding of how to prevent transmission to other family members.

Keywords: Pulmonary Tuberculosis, Nursing Care, Security and Safety Needs

\section{PENDAHULUAN}

\section{Latar Belakang}

Tubercolusis merupakan penyakit infeksi menular yang yang disebabkan oleh mikobakterium tubercolusis yang menyerang paru-paru dan hampir seluruh organ tubuh lainya (Amin, 2015).

Menurut data World Health Organization (WHO) tahun 2018 diperkiraan ada 10,4 juta kasus TB Paru di seluruh dunia, dan 1,7 juta meninggal karena penyakit TB paru, dimana 6,2 juta sejumlah laki-laki 3,2 juta adalah perempuan. Indonesia termasuk dalam tujuh negara yang menyumbang $64 \%$ dari kasus-kasus baru di dunia dan menjadi urutan kedua setelah india dengan penderita TB paru tertinggi di dunia secara global, angka kematian TB paru mengalami penurunan sebesar $37 \%$ antara tahun 2000 dan 2016.

Menurut kementrian RI (2017) jumlah kasus TB paru BTA (+) terbanyak di provinsi jawa barat sekitar 31.598, diikuti jawa timur 33.585, jawa tengah 18.248, DKI jakarta 12.597, sumatera utara 11.897, 
banten 7.400 , sumatera barat 4.541 , dan sulawesi selatan 4.314, penderita TB paru disetiap provinsi mengalami peningkatan dan penurunan. Pada tahun 2017 penderita TB paru yang sembuh, kemudian mengalami penurunan yaitu papua barat sebanyak $528 \%$ penderita TB paru. Adapun jumlah kasus tuberkulosis paru di sulawesi selatan 8.508, penderita TB paru. Pada tahun 2017 provinsi yang mengalami penurunan yaitu diprovinsi Gorontalo sebanyak 10\%. (Profil Dinas Kesehatan, 2017)

Berdasarkan data penderita Tuberkulosis Paru di Rumah Sakit Tingkat II Pelamonia Makassar pada tahun 2017-2018 mencapai 1054 kasus Tuberkulosis Paru. Angka ini meningkat signifikan dibandingkan tahun sebelumnya hanya 1002 kasus Tuberkulosis Paru.

Tuberkulosis merupakan penyakit lama yang masih menjadi pembunuh terbanyak diantara penyakit menular. Dunia pun masih belum bebas dari TBC. Penderita yang belum diperiksa dan diobati akan menjadi sumber penularan bagi orang di sekitarnya. Hal ini yang menyebabkan seakan-akan masalah TBC tak kunjung selesai. Dunia ingin mencapai eliminasi TBC pada tahun 2030 dan Indonesia turut berkomitmen mencapainya. (Kementrian Kesehatan RI, 2017)

Besar dan luasnya permasalahan akibat TBC mengharuskan semua pihak untuk dapat berkomitmen dan bekerjasama dalam melakukan pencegahan dan pengendalian TBC. Kerugian yang diakibatkannya sangat besar, bukan hanya dari aspek kesehatan semata tetapi juga dari aspek sosial maupun ekonomi. Dengan demikian TBC merupakan ancaman terhadap cita-cita pembangunan dalam meningkatkan kesejahteraan rakyat secara menyeluruh, karenanya perang terhadap TBC berarti pula perang terhadap kemiskinan, ketidakproduktifan dan kelemahan akibat TBC. (Kementrian Kesehatan $\mathrm{RI}, 2017$ )

Tuberkulosis sering dijuluki "the great iminator" yaitu suatu penyakit yang mempunyai banyak kemiripan dengan penyakit lain yang juga memberikan gejala umum seperti lemah dan demam. Pada sejumlah penderita gejala yang timbul tidak jelas sehingga sering diabaikan bahkan kadangkadang asimtomatik.

Efek yang timbul jika tidak ditangani dengan baik maka akan menimbulkan komplikasi seperti : malnutrisi, empiema, efusi pelura, hepatitis, ketulian dan gangguan gastrointestinal (sebagai efek samping obat-obatan). Komplikasi Menurut Wahid \& Imam (2013), dampak masalah yang sering terjadi padaTB paru adalah: Hemoptisis berat (perdarahan dari saluran nafas bawah) yang dapat mengakibatkan kematian karena syok hipovolemik atau tersumbatnya jalan nafas, Kolaps dari lobus akibat retraksi bronchial, Bronkiektasis (peleburan bronkus setempat) dan fibrosis (pembentukan jaringan ikat pada proses pemulihan atau reaktif) pada paru, Pneumothorak (adanya udara dalam rongga pleura) spontan: kolaps spontan karena kerusakan jaringan paru, Penyebaran infeksi ke organ lain seperti kardiopulmonar (Chardio Pulmonary Insuffciency). (Abd wahid; Imam Suprapto, 2013)

Salah satu upaya untuk mencegah efek yang ditimbulkan maka diperlukan upaya pencegahan dan pemberantasan TB paru yang dilakukan dengan pendekatan Directly Observe Treatment Shortcourse (DOTS) atau pengobatan TB paru dengan pengawasan langsung oleh Pengawas Menelan Obat (PMO) sehingga diharapkan dapat membantu penderita TB paru dalam pemenuhan kebutuhan keamanan dan keselamatan agar terhindar dari risiko penyebaran infeksi dan dapat menurunkan resiko penyakit TB paru serta dapat mengurangi pasien yang mengalami penurunan kemampuan untuk melindungi dirinya dari penyakit, baik dari luar maupun dari dalam tubuh.

Penanganan penyakit Tuberkulosis Paru pada kebutuhan keamanan dan keselamatan melibatkan banyak unsur termasuk didalamnya perawat yang berperan sebagai fasilitas perawatan kesehatan yang akan memberikan perawatan pada pasien TB paru dalam pemenuhan kebutuhan keamanan dan keselamatan yang dapat mencegah timbulnya pertumbuhan bakteri dan penularan pada orang lain. Oleh karena itu, harapan dari peneliti adalah agar penderita Tuberkulosis Paru bisa sembuh dan mencegah timbulnya komplikasi serta mencegah penularan pada orang lain agar dapat menurunkan angka kematian dari pada pasien TB paru.

Tujuan studi Kasus

Menggambarkan penerapan asuhan keperawatan pada pasien tuberkulosis paru dalam pemenuhan kebutuhan keamanan dan keselamatan

\section{Rencana studi kasus}

Penelitian ini menggunakan rancangan studi kasus deksriptif. Data dari hasil penelitian di sajikan dalam bentuk studi kasus dengan menggunakan pendekatan proses keperawatan.

Penelitian studi kasus adalah studi yang mengeksplorasikan suatu masalah keperawatan dengan batasan terperinci, memiliki pengambilan data yang mendalam dan menyertakan berbagai sumber informasi. (Rahardjo, 2017)

\section{Subjek studi kasus}

Subjek stadi kasus yang akan dikaji adalah pasien dengan penyakit Tuberkulosis Paru dalam pemenuhan kebutuhan Keamanan dan Keselamatan.

\section{Fokus studi kasus}

Studi kasus berfokus pada pasien Tuberkulosis Paru yang mengalami gangguan pemenuhan kebutuhan Keamanan dan Keselamatan 


\section{Tempat dan waktu}

Tempat pelaksanaan studi kasus bertempat di ruang Sakura Rumah Sakit Tingkat II Pelamonia Makassar

Waktu pelaksanaan studi kasus pada tanggal 11 s/d 15 Juni 2019

\section{Pengumpulan data}

Tehnik pengumpulan data yang di gunakan yaitu: wawancara dan observasi

\section{Penyajian data}

Data yang telah terkumpul dari hasil pengumpulan data yang di peroleh dari pasien di sajikan secara tekstural/narasi dari subjek studi kasus yang merupakan data pendukungnya.

\section{HASIL STUDI KASUS}

Gambaran umum lokasi pelaksanaan studi kasus

Penelitian ini dilaksanakan di Ruangan Sakura, Rumah Sakit Tingkat II (RS TK II) Pelamonia Makassar. yang terletak di Jalan Jend. Sudirman No. 27, Pisang Utara, Kec. Ujung Pandang, Kota Makassar.

\section{Data Umum Subyek Studi Kasus}

Hasil dari pengkajian diperoleh data, Klien mengatakan sering mengalami pusing pada saat beraktivitas, klien mengatakan pusing seperti penglihatan berkunang-kunang pada saat bangun dari tempat tidur, klien mengatakan penglihatan kabur, klien mengatakan kesulitan berjalan dengan sendirinya tanpa bantuan keluarganya, klien mengatakan adanya perasaan lelah, cemas dan takut jatuh. Klien mengatakan pada saat dirumah klien tidak memakai masker, klien mengatakan tidak rutin mencuci tangan dan klien mengatakan pada saat batuk klien tidak menutup mulut. Klien nampak pusing, klien nampak lemah, klien nampak pucat, tingkat kesadaran composmentis, klien mengalami anemia dengan nilai hemoglobin $5,9 \mathrm{~g} / \mathrm{dl}$, klien nampak tidak memakai masker pada saat kontak dengan orang lain, klien nampak tidak menutup mulut pada saat batuk, klien tidak mempunyai tempat khusus untuk membuang sputumnya, lingkungan klien nampak kurang bersih, keadaan umum lemah, dengan TD: 160/90 mmHg, Nadi: $88 \mathrm{x} /$ menit, Suhu: $36,5^{\circ} \mathrm{C}$, Pernafasan: 24x/menit, TB : $140 \mathrm{~cm}, \mathrm{BB}: 45$ $\mathrm{kg}$ bibir pecah-pecah, bibir kering, lidah kotor, membran mukosa pucat, rongga mulut kotor, kulit kering, turgor kulit jelek, tonus otot kurang, konjungtiva anemis, rambut kering, dan rambut beruban. Pada pemeriksaan laboratorium pada tanggal 11 Juni 2019 hasil hemoglobin $5,9 \mathrm{~g} / \mathrm{dl}$ (normal : 13,8-17,2 g/dl), RBC 2,21 x103/ml (normal : $4,2-5,9 \times 10^{3} / \mathrm{ml}$ ), PLT $515 \times 10^{3} / \mathrm{ml}$ (normal : 150-390 x 103/ml), LED >150 mm/jam (normal : <20 mm/jam), GDS $304 \mathrm{mg} / \mathrm{dL}$ (normal : $70-130 \mathrm{mg} / \mathrm{dl}$ ), SGOT 29 U/L (normal : 3-45 u/L), SGPT $10 \mathrm{U} / \mathrm{L}$ (normal : 0-35 $\mathrm{u} / \mathrm{L})$. Pemeriksaan penunjang pada tanggal 10 Juni 2019 yaitu foto thorax hasil Tb paru lama nonaktif.
Riwayat kesehatan masa lalu, mengatakan ia memiliki riwayat penyakit Tuberkulosis Paru dan Diabetes Mellitus sejak 6 tahun yang lalu.

\section{Diagnosa}

Diagnosa keperawatan yang muncul dari hasil pengkajian dan observasi, Adapun prioritas masalah, yaitu :

Diagnosa Pertama yaitu : Resiko cedera/jatuh berhubungan dengan kelemahan yang ditandai dengan : Faktor resiko : klien mengalami anemia dengan nilai hemoglobin 5,9 g/dl dan PLT : $515 \times 10^{3}$, klien pusing pada saat beraktivitas, penglihatan klien berkunang-kunang pada saat bangun dari tempat tidur, penglihatan klien kabur, klien kesulitan berjalan dengan sendiri, klien mengalami kelemahan, cemas dan juga adanya rasa takut untuk jatuh. Pemeriksaan penunjang yaitu foto thorax hasil TB paru lama nonaktif, keadaan umum lemah dengan TD: 160/90 mmHg, Nadi: $88 \mathrm{x} /$ menit, Suhu: $36,5^{\circ} \mathrm{C}$, Pernafasan: 24x/menit

Diagnosa Kedua yaitu : Resiko penyebaran infeksi berhubungan dengan penurunan system imun, aspek kronik penyakit. Faktor resiko : klien batuk tidak menggunakan penutup mulut, klien sehari-hari tidak menggunakan masker, keluarga dan klien dilingkungannya tidak menggunakan masker, tidak terdapat wadah untuk tempat sputum klien dan lingkungan nampak kurang bersih, klien mengalami anemia dengan nilai hemoglobin 5,9 g/dl dan PLT : $515 \times 10^{3}$ dan klien mengalami tekanan darah tinggi $(160 / 90 \mathrm{mmHg})$

Dan Diagnosa Ketiga adalah Perubahan proteksi berhubungan defisit imunologi. Data subjektif : Klien mengatakan sering mengalami pusing pada saat beraktivitas, klien mengatakan pusing seperti penglihatan terputar-putar pada saat bangun dari tempat tidur, klien mengatakan penglihatan kabur, klien mengatakan pada saat dirumah klien tidak memakai masker, klien mengatakan tidak rutin mencuci tangan, klien mengatakan pada saat kontak dengan orang lain klien tidak memakai masker, klien mengatakan pada saat batuk klien tidak menutup mulut, klien mengatakan tidak rutin mencuci tangan

Data objektif : klien nampak lemah, klien nampak pucat, klien mengalami anemia, klien mengalami tekanan darah tinggi, Klien mengatakan pada saat dirumah klien tidak memakai masker, klien tidak rutin mencuci tangan, klien nampak tidak menggunakan masker, klien batuk tidak menggunakan penutup mulut. Dari hasil pemeriksaan laboratorium didapatkan hasil hemoglobin $5,9 \mathrm{~g} / \mathrm{dl}$, RBC 2,21 x103/ml, PLT $515 \times 10^{3} / \mathrm{ml}$, LED >150 mm/ dan GDS $304 \mathrm{mg} / \mathrm{dL}$. Dari pemeriksaan didapatkan data keadaan umum lemah, tingkat kesadaran composmentis dengan TD: 160/90 mmHg, Nadi: 88 $\mathrm{x} /$ menit, Suhu: $36,5^{\circ} \mathrm{C}$, Pernafasan: $24 \mathrm{x} /$ menit. 


\section{Intervensi Keperawatan}

Intervensi keperawatan dari diagnosa Resiko cedera berhubungan dengan kelemahan yaitu : Kaji dan identifikasi faktor risiko cedera yang mungkin terjadi pada pasien, Identifikasi kemampuan pasien untuk berjalan, berpindah, dan aktivitas, Kaji kemampuan pasien dalam menggunakan alat bantu jalan seperti kruk, tripot, dan lain-lain. Jaga kebersihan lantai kamar, Gunakan alas kaki pasien yang tidak licin dengan hak rendah, Jaga kebersihan tempat tidur, laken bersih dan kencang, Tempatkan barang-barang berbahaya ditempat yang aman, Bantu pasien dalam melakukan aktivitas dan mobilisasi, Lakukan perubahan posisi setiap 2 jam pada pasien tirah baring, Berikan pendidikan kesehatan pada keluarga tentang risiko cedera pada jatuh,

Intervensi untuk diagnosa Resiko penyebaran infeksi berhubungan dengan penurunan system imun yaitu : Bersihkan lingkungan setelah dipakai pasien lain, Batasi pengunjung bila perlu, Instruksikan pada pengunjung untuk mencuci tangan saat berkunjung dan setelah berkunjung meninggalkan pasien, Gunakan sabun antimikrobia untuk cuci tangan, Cuci tangan setiap sebelum dan sesudah makan,

Intervensi untuk Diagnosa Perubahan proteksi berhubungan defisit imunologi yaitu : Kaji kembali risiko pasien yang terjadi infeksi, Kaji status nutrisi pasien, Observasi tanda vital, tekanan darah, suhu, nadi dan pernapasan setiap 4 jam, Kaji hasil laboratorium seperti $\mathrm{Hb}$, Instruksikan untuk memberi perlindungan khusus, seperti penggunaan masker dan menggunakan tisu pada saat batuk, Anjurkan pasien untuk meningkatkan tidur yang cukup, Anjurkan pasien untuk menghindari keadaan stres,

\section{Implementasi Keperawatan}

Berdasarkan intervensi keperawatan dari prioritas masalah yang muncul, adapun Implementasi sebagai berikut :

Pada Diagnosa Resiko Cedera/jatuh yaitu: Mengkaji dan mengidentifikasi faktor risiko cedera yang mungkin terjadi pada pasien. Hasil : faktor risiko yang mungkin terjadi pada pasien adalah kelemahan fisik dan pusing yang dapat menyebabkan pasien cedera/jatuh

Mengidentifikasi kemampuan pasien untuk berjalan, berpindah dan aktivitas. Hasil : pasien belum mampu dalam berjalan, berpindah dan beraktivitas, pasien harus dibantu oleh keluarga

Mengkaji kemampuan pasien dalam menggunakan alat bantu jalan seperti kruk, tripot, dan lain-lain. Hasil : pasien mampu dalam menggunakan alat bantu jalan tetapi lebih ingin dibantu oleh keluarganya

Menjaga kebersihan lantai kamar. Hasil : lantai kamar pasien belum bersih
Menggunakan alas kaki pasien yang tidak licin dengan hak rendah. Hasil : pasien tidak menggunakan alas kaki.

Menjaga kebersihan tempat tidur, laken bersih dan kencang. Hasil : tempat tidur pasien kurang bersih, laken terlipat dan tidak kencang.

Menempatkan barang-barang berbahaya ditempat yang aman Hasil : pisau diletakkan diatas meja.

Membantu pasien dalam melakukan aktivitas dan mobilisasi. Hasil : pasien dibantu oleh keluarganya.

Melakukan perubahan posisi setiap 2 jam pada pasien tirah baring Hasil : pasien belum melakukan apa yang telah diinstruksikan.

Memberikan pendidikan kesehatan pada keluarga tentang risiko pada cedera jatuh. Hasil : keluarga pasien mengerti dan sekarang telah mengetahui bagaimana cara merawat agar tidak terjadi cedera/jatuh

\section{Evaluasi Keperawatan}

Evaluasi dilakukan dengan metode SOAP yaitu:

Pada Diagnosa Resiko Cedera/Jatuh : Data subjektif : pasien mengatakan masih merasa pusing pada saat beraktivitas, pasien mengatakan masih merasa pusing seperti penglihatan berkunangkunang pada saat bangun dari tempat tidur, pasien mengatakan penglihatan masih kabur, pasien mengatakan masih kesulitan berjalan, pasien mengatakan perasaan lelah, cemas dan takut jatuh. Data objektif : pasien tidak ada cedera. Pasien tampak dipapah saat berjalan ke kamar mandi Assesmen : Masalah belum teratasi. Planning : Pertahankankan intervensi.

Pada Diagnosa Resiko Penyebaran Infeksi : Data subjektif : pasien mengatakan masih lemah, pasien mengatakan pada saat dirumah pasien akan memakai masker, pasien mengatakan akan rutin mencuci tangan, pasien mengatakan pada saat kontak dengan orang lain pasien akan memakai masker dan pasien mengatakan pada saat batuk klien akan menutup mulut. Data objektif : pasien nampak membersihkan tempat tidur setelah dipakai oleh pasien lain, pasien nampak membatasi pengunjung yang datang, pengunjung nampak mencuci tangan pada saat berkunjung dan setelah berkunjung kepasien, pasien nampak menggunakan sabun antimikrobia dan pasien nampak mencuci tangan sebelum dan setelah makan. Assesmen : masalah belum teratasi. Planning : pertahankan intervensi.

Pada Diagnosa Perubahan Proteksi : Data subjektif : pasien mengatakan masih pusing pada saat beraktivitas, pasien mengatakan rasa pusing seperti penglihatan berkunang-kunang pada saat bangun dari tempat tidur, pasien mengatakan pada saat dirumah akan memakai masker, pasien 
mengatakan akan rutin mencuci tangan, pasien mengatakan pada saat kontak dengan orang lain akan memakai masker, pasien mengatakan pada saat batuk akan menutup mulut, pasien mengatakan akan rutin mencuci tangan, pasien mengatakan akan meningkatkan tidur yang cukup dan pasien mengatakan berusaha menghindari keadaan stres. Data objektif : pasien telah menggunakan masker pada saat kontak dengan orang lain, pasien nampak pada saat batuk telah menutup mulutnya. Asessmen : masalah belum teratasi. Planning : Lanjutkan intervensi.

\section{PEMBAHASAN \\ Pengkajian}

Berdasarkan hasil penelitian pada studi kasus yang terjadi pada klien dengan diagnosa medis TB Paru On Treatment maka pada bagian ini penulis akan menguraikan hasil yang diperoleh selama pelaksanaan studi kasus yang meliputi :

a) Klien mengatakan sering mengalami pusing pada saat beraktivitas, disebabkan karena anemia yang dialaminya. Menurut Jurnal Majority (2015) anemia merupakan komplikasi tersering pada penderita TB yang menyebabkan pusing pada saat beraktivitas. Klien mengatakan pusing seperti penglihatan berkunang-kunang pada saat bangun dari tempat tidur, disebabkan karena anemia yang dialaminya. Menurut Unnes Journal of Public Health (2017) hal ini disebabkan karena perubahan metabolik pada pasien TB paru seperti kurangnya sel darah yang menyebabkan pusing seperti penglihatan berkunangkunang.

b) Klien mengatakan penglihatan kabur, disebabkan karena penurunan tajam penglihatan. Hal ini sejalan dengan (Wartonah, 2015) bahwa penglihatan kabur disebabkan oleh penurunan tajam penglihatan

c) Klien mengatakan kesulitan berjalan dengan sendirinya tanpa bantuan keluarganya, disebabkan karena kelemahan fisik sehingga klien sulit berjalan dengan sendirinya. Menurut (Wartonah, 2015) bahwa rasa kelemahan fisik disebabkan darah dalam tubuh yang kurang (anemia) sehingga mengakibatkan kelemahan fisik.

d) Klien mengatakan adanya perasaan lelah, disebabkan karena kurang darah dalam tubuh sehingga mengalami kelemahan dan keletihan. Menurut (Wartonah, 2015) bahwa rasa lelah disebabkan oleh kurangnya darah didalam tubuh.

e) Klien mengatakan cemas, disebabkan karena kurangnya pengetahuan tentang penyakit sehingga mengalami kecemasan. Hal ini sejalan dengan pendapat Ibrahim (2012) yang mengatakan bahwa kecemasan terjadi karena keadaan emosional yang berhubungan dengan suatu ancaman. Suatu ancaman yang dimaksud adalah tentang bagaimana kedepannya soal penyakit yang dideritanya sehingga mengakibatkan kecemasan karena kurangnya pengetahuan tentang penyakit.

f) Klien mengatakan takut jatuh, disebabkan karena kurangnya informasi tentang keamanan sehingga klien mengalami perasaan takut jatuh. Menurut (Wartonah, 2015) perasaan takut jatuh disebabkan oleh kurangnya informasi tentang keamanan. Faktor risiko yang mungkin terjadi pada klien adalah kelemahan fisik dan pusing yang dapat menyebabkan pasien cedera/jatuh sehingga klien mengalami rasa takut jatuh. Klien mengatakan pada saat dirumah dan dirumah sakit tidak memakai masker, disebabkan karena kurangnya pengetahuan tentang penyebaran infeksi. Hal ini sependapat dengan Isminah yang mengutip penelitian Linda tentang penyakit Tuberkulosis paru dapat terjadi karena adanya perilaku dan sikap keluarga yang kurang baik. Kurangnya perilaku keluarga tersebut ditunjukkan dengan tidak menggunakan masker debu (jika kontak dengan pasien). Terjadinya perilaku yang kurang baik dari keluarga karena kurangnya pengetahuan dan sikap keluarga tentang pencegahan penyakit menular yaitu TB.

g) Klien mengatakan pada saat kontak dengan orang lain klien tidak memakai masker, disebabkan karena kurangnya pengetahuan tentang penularan infeksi pada penyakitnya. Menurut (Smeltzer, 2012) jika kontak dengan orang lain tidak memakai masker dapat menyebabkan penularan infeksi dan gampang masuknya patogen.

h) Klien mengatakan pada saat batuk klien tidak menutup mulut, disebabkan karena ketidakcukupan pengetahuan untuk menghindari paparan patogen yang masuk kedalam tubuh. Hal ini sependapat dengan (Smeltzer, 2012) yang mengatakan bahwa apabila pada saat batuk tidak menutup mulut maka akan mengakibatkan percikan dahak (droplet nuclei) yang akan mengenai orang yang ada disekitarnya sehingga mengakibatkan penularan infeksi.

i) Klien tidak mempunyai tempat khusus untuk menempati sputumnya, disebabkan oleh kurang pengetahuan tentang penyakitnya. Menurut Wahyuni Indarwati (2015) yang mengatakan bahwa kurangnya pengetahuan tentang penyakit dapat menyebabkan penularan penyakit yang diderita oleh pasien.

Diagnosa

Berdasarkan pengkajian yang dilakukan maka diagnosa keperawatan klien adalah :

1) Resiko cedera/jatuh berhubungan dengan kelemahan, ditandai dengan :

faktor resiko : klien mengalami anemia dengan nilai hemoglobin 5,9 g/dl dan PLT : $515 \times 10^{3}$, klien pusing pada saat beraktivitas, penglihatan klien berkunangkunang pada saat bangun dari tempat tidur, penglihatan klien kabur, klien kesulitan berjalan dengan sendiri, klien mengalami kelemahan, cemas dan juga adanya rasa takut untuk jatuh. Pemeriksaan penunjang yaitu foto thorax hasil TB paru lama 
nonaktif. Dari pemeriksaan pada klien didapatkan keadaan umum lemah dengan TD: $160 / 90 \mathrm{mmHg}$, Nadi: $88 \mathrm{x} / \mathrm{menit}$, Suhu: $36,5^{\circ} \mathrm{C}$, Pernafasan: 24x/menit, TB : $140 \mathrm{~cm}, \mathrm{BB}: 45 \mathrm{~kg}$. Pada pemeriksaan laboratorium pada tanggal 11 Juni 2019 hasil hemoglobin 5,9 g/dl (normal : 13,8-17,2 g/dl), RBC 2,21 x103/ml (normal : 4,2-5,9 x103/ml), PLT 515 $\mathrm{x} 10^{3} / \mathrm{ml}$ (normal : $150-390 \times 10^{3} / \mathrm{ml}$ ), LED >150 $\mathrm{mm} / \mathrm{jam}$ (normal : $<20 \mathrm{~mm} / \mathrm{jam}$ ), GDS $304 \mathrm{mg} / \mathrm{dL}$ (normal : 70-130 mg/dl), SGOT $29 \mathrm{U} / \mathrm{L}$ (normal : 3$45 \mathrm{u} / \mathrm{L}$ ), SGPT $10 \mathrm{U} / \mathrm{L}$ (normal : 0-35 u/L). Menurut (Wartonah, 2015) resiko cedera atau jatuh yang berhubungan dengan kelemahan disebabkan karena kurangnya darah dalam tubuh yang menyebabkan pusing, penglihatan berkunang-kunang pada saat bangun dari tempat tidur dan juga kesulitan pada saat berjalan.

2) Resiko penyebaran infeksi berhubungan dengan penurunan system imun, aspek kronis penyakit, ditandai dengan :

Data fokus yaitu faktor resiko : klien batuk tidak menggunakan penutup mulut, klien sehari-hari tidak menggunakan masker, keluarga dan klien dilingkungannya tidak menggunakan masker, tidak terdapat wadah untuk tempat sputum klien dan lingkungan nampak kurang bersih, klien mengalami anemia dengan nilai hemoglobin $5,9 \mathrm{~g} / \mathrm{dl}$ dan PLT : $515 \times 10^{3}$ dan klien mengalami tekanan darah tinggi. Hal ini sependapat dengan (Smeltzer, 2012) yang mengatakan bahwa jika infeksi menyebar keseluruh bagian tubuh maka akan mengakibatkan bakteri yang ada didalam tubuh bertambah dan akan sulit disembuhkan, disebabkan karena tidak adekuatnya pertahankan didalam tubuh.

3) Perubahan proteksi berhubungan dengan defisit imunologi, ditandai dengan : Data subjektif : Klien mengatakan sering mengalami pusing pada saat beraktivitas, klien mengatakan pusing seperti penglihatan terputar-putar pada saat bangun dari tempat tidur, klien mengatakan penglihatan kabur, klien mengatakan pada saat dirumah klien tidak memakai masker, klien mengatakan tidak rutin mencuci tangan, klien mengatakan pada saat kontak dengan orang lain klien tidak memakai masker, klien mengatakan pada saat batuk klien tidak menutup mulut, klien mengatakan tidak rutin mencuci tangan. Data objektif : klien nampak lemah, klien nampak pucat, klien mengalami anemia, klien mengalami tekanan darah tinggi, klien tidak rutin mencuci tangan, klien nampak tidak menggunakan masker, klien batuk tidak menggunakan penutup mulut. Dari hasil pemeriksaan laboratorium didapatkan hasil hemoglobin 5,9 g/dl, RBC 2,21 x103/ml, PLT 515 $\mathrm{x} 10^{3} / \mathrm{ml}$, LED $>150 \mathrm{~mm} /$ dan GDS $304 \mathrm{mg} / \mathrm{dL}$, keadaan umum lemah, tingkat kesadaran composmentis dengan TD: 160/90 mmHg, Nadi: 88 $\mathrm{x} /$ menit, Suhu: $36,5^{\circ} \mathrm{C}$, Pernafasan: $24 \mathrm{x} /$ menit.

Intervensi
Intervensi keperawatan pada diagnosa pertama pada klien yaitu tindakan keperawatan yang dilakukan selama 3 hari, diharapkan resiko cedera/jatuh berhubungan dengan kelemahan tidak terjadi dengan kriteria : cedera/jatuh tidak terjadi dan pasien menunjukkan perilaku pencegahan terjadinya cedera Intervensi yang dapat dibuat berdasarkan diagnosa keperawatan tersebut adalah :

a. Kaji dan identifikasi faktor risiko cedera yang mungkin terjadi pada pasien

Intervensi ini perlu dilakukan karena faktor risiko cedera yang dapat mempengaruhi kebebasan dalam bergerak yang disebabkan oleh kelemahan fisik. Hal ini sependapat degan (Wartonah, 2015) yang mengatakan bahwa pentingnya mengkaji dan mengidentifikasi kembali faktor risiko yang mungkin terjadi pada pasien seperti lantai yang licin

b. Identifikasi kemampuan pasien untuk berjalan, berpindah, dan aktivitas

Hal ini perlu dilakukan untuk mengetahui kemampuan pasien untuk berjalan, berpindah dan beraktivitas. Salah satu yang dapat menimbulkan cedera jatuh adalah ketidakmampuan pasien berjalan dan aktivitas yang tidak sempurna

c. Kaji kemampuan pasien dalam menggunakan alat bantu jalan seperti kruk, tripot, dan lain-lain

Intervensi ini perlu dilakukan karena untuk mengetahui ketidakmampuan pasien dalam menggunakan alat bantu jalan, pasien dapat terpeleset dan jatuh

d. Jaga kebersihan lantai kamar

$\mathrm{Hal}$ ini perlu dilakukan karena lantai licin dapat menyebabkan pasien mengalami cedera. Menurut Hafizhatun Nadia (2017) yang mengatakan bahwa adanya hubungan antara lantai licin dapat menyebabkan cedera pada pasien.

e. Gunakan alas kaki pasien yang tidak licin dengan hak rendah

Hal ini perlu dilakukan karena alas kaki yang rendah dapat menghindari pasien dari resiko jatuh.

f. Jaga kebersihan tempat tidur, laken bersih dan kencang. Ini perlu dilakukan untuk menghindari risiko gangguan integritas kulit atau dekubitus pada pasien yang tirah baring.

g. Tempatkan barang-barang berbahaya ditempat yang aman. Hal ini dilakukan agar mampu menghindari pasien dan keluarga dari benda/barang yang berbahaya seperti pisau dan gunting

h. Bantu pasien dalam melakukan aktivitas dan mobilisasi. Hal ini perlu dilakukan agar dapat membantu pasien untuk melakukan aktivitas dan bermobilisasi jadi pasien juga dapat beraktivitas dengan baik dan untuk menghindari dari trauma

i. Lakukan perubahan posisi setiap 2 jam pada pasien tirah baring. Hal ini perlu dilakukan karena penekanan yang lama pada bagian tubuh yang tertekan dapat menimbulkan hipoksia jaringan. 
j. Berikan pendidikan kesehatan pada keluarga tentang risiko cedera pada jatuh. Ini perlu dilakukan karena keluarga akan dilibatkan dalam perawatan pasien terutama dalam menjaga pasien supaya tidak jatuh atau cedera

Untuk diagnosa yang kedua yaitu resiko penyebaran infeksi berhubungan dengan penurunan system imun, aspek kronis penyakit. Setelah dilakukan tindakan keperawatan selama 3 hari, diharapkan resiko penyebaran infeksi berhubungan dengan penurunan system imun, aspek kronis penyakit teratasi dengan kriteria : pasien tidak mengalami penyebaran infeksi, system imun kembali pulih dan pasien menunjukkan perilaku pencegahan terjadinya penyebaran infeksi.

Intervensi yang dibuat sesuai diagnosa keperawatan adalah :

a. Bersihkan lingkungan setelah dipakai pasien lain Intervensi ini perlu dilakukan karena agar tidak terjadi penularan infeksi. Hal ini dapat disebabkan karena lingkungan pasien tidak bersih apalagi setelah dipakai oleh pasien lain, kemungkinan ada bakteri yang menempel jika belum dibersihkan dengan baik

b. Batasi pengunjung

Hal ini perlu dilakukan agar pasien bisa tenang dalam beristirahat dan juga untuk mencegah terjadinya perluasan infeksi pada pengunjung yang datang menjenguk pasien yang tidak menggunakan alat pelindung diri seperti masker

c. Instruksikan pada pengunjung untuk mencuci tangan saat berkunjung dan setelah berkunjung meninggalkan pasien. Ini perlu dilakukan agar dapat mengurangi bakteri yang menempel pada bagian tubuh bagi pengunjung

d. Gunakan sabun antimikrobia untuk cuci tangan, agar dapat membunuh bakteri yang menempel pada tangan dan juga sela-sela jari

e. Cuci tangan setiap sebelum dan sesudah makan. Intervensi ini dilakukan agar dapat menghindari bakteri dan penularan infeksi yang terjadi

Diagnosa ketiga yaitu perubahan proteksi berhubungan dengan defisit imunologi. setelah dilakukan tindakan keperawatan selama 3 hari, diharapkan perubahan proteksi berhubungan dengan defisit imunologi teratasi dengan kriteria : Pasien terhindar dari infeksi dan pasien dapat menunjukkan perilaku yang dapat mencegah terjadinya perluasan infeksi.

Intervensi yang dibuat sesuai diagnosa keperawatan adalah :

a. Kaji kembali risiko pasien yang terjadi infeksi. Intervensi ini diperlukan karena hal ini menunjukkan data dasar untuk menentukan rencana tindakan tindak lanjut dan tidak terjadi perluasan infeksi

b. Kaji status nutrisi pasien. Hal ini diperlukan karena nutrisi pasien merupakan penyokong daya tahan tubuh pasien. Menurut Irandi Putra Pratomo (2012) penurunan status imun akibat malnutrisi mengakibatkan peningkatan pertumbuhan mikroorganisme jadi diperlukan nutrisi yang baik bagi pasien yang mengalami penyakit tuberkulosis paru agar sistem imun kuat dan juga tidak mengalami pertumbuhan mikroorganisme lainnya.

c. Observasi tanda vital, tekanan darah, suhu, nadi dan pernapasan setiap 4 jam. Hal ini perlu dilakukan karena untuk mengetahui keadaan umum pasien terutama pada peningkatan suhu tubuh yang merupakan salah satu indikasi adanya infeksi, yang berarti terjadi penurunan daya tahan tubuh jika terjadi peningkatan suhu tubuh

d. Kaji hasil laboratorium seperti $\mathrm{Hb}$

Intervensi ini dilakukan karena untuk mengetahui jumlah darah yang didalam tubuh. $\mathrm{Hb}$ yang rendah merupakan indikasi penurunan daya tahan tubuh. Hal ini sependapat dengan Satrio Wahyu Sadewo (2014) yang mengatkan bahwa kurang kadar darah dalam tubuh dapat engakibatkan turunnya daya tahan tubuh

e. Gunakan perlindungan khusus, seperti penggunaan masker dan menggunakan tisu pada saat batuk Hal ini perlu dilakukan karena perlindungan khusus juga dapat mencegah masuknya mikroorganisme kedalam tubuh. Penggunaan masker dan tisu dapat mengurangi penularan secara droplet dan melalui udara

f. Jaga kebersihan diri pasien

Ini perlu dilakukan karena tubuh yang kotor dan lingkungan yang tidak bersih merupakan media pertumbuhan penyakit

g. Penatalaksanaan dengan tim medis dalam pemberian obat untuk meningkatkan daya tahan tubuh

Intervensi ini perlu dilakukan karena pemberian vitamin terbukti dapat meningkatkan daya tahan tubuh, agar daya tahan tubuh kuat dan tidak gampang terkena infeksi/bakteri

h. Anjurkan pasien untuk meningkatkan tidur yang cukup

Ini perlu dilakukan karena kualitas tidur yang cukup dapat membantu memulihkan stamina tubuh

i. Anjurkan pasien untuk menghindari keadaan stres Hal ini perlu dilakukan karena stres dapat meningkatkan metabolisme tubuh dan menimbulkan ketidakseimbangan energi

Implementasi

Implementasi adalah menginformasikan hasil dan cara berkomunikasi dengan klien dan anggota tim layanan kesehatan lain. Secara individual atau dalam konferensi perencanaan. Menuliskan informasi dengan cara mendokumentasikannya sehingga penyedia layanan kesehatan selanjutnya dapat melakukan tindakan dengan tujuan dan pemahaman. (Roshdahl, 2014)

Berdasarkan intervensi pada diagnosa keperawatan yang pertama yaitu tindakan yang dilakukan selama 3 hari dengan 10 intervensi dengan hasil : tidak ada cedera yang terjadi pada pasien, 
pasien tidak merasa pusing lagi, pasien sudah tidak lemas dan takut jatuh

Untuk diagnosa keperawatan yang kedua yaitu tindakan yang dilakukan selama 3 hari dengan 5 intervensi dengan hasil : tempat tidur pasien bersih, pengunjung telah dibatasi, pasien dan pengunjung menggunakan hand hygiene.

Dan untuk diagnosa yang ketiga yaitu tindakan yang dilakukan selama 3 hari dengan 11 intervensi dengan hasil : pasien melaksanakan diet 2100 kalori, frekuensi makannya sedikit tapi sering, porsi makannya dihabiskan, tekanan darah mulai menurun, pasien telah menggunakan masker pada saat kontak dengan orang lain dan pasien menutup mulutnya pada saat batuk.

\section{Evaluasi}

Evaluasi adalah pengukuran keefektifan pengkajian, diagnosa, perencanaan dan implementasi. Langkah-langkah dalam mengevaluasi asuhan keperawatan adalah menganalisis respon klien, mengidentifikasi factor yang berkontribusi terhadap keberhasilan atau kegagalan dan perencanaan untuk asuhan di masa depan. (Roshdahl, 2014)

Berdasarkan kasus yang telah ditemukan pada diagnosa yang pertama maka dapat didapatkan hasil dari evaluasinya adalah : pada tanggal 11 Juni 2019 masalah belum teratasi karena masih menunjukkan tanda-tanda risiko cedera/jatuh seperti masih sulit berjalan tanpa bantuan keluarga dan pasien masih merasa pusing. Pada tanggal 12 Juni 2019 masalah belum teratasi karena pasien menjaga kebersihan lingkungan sekitarnya seperti lantai yang licin yang dapat menyebabkan pasien mengalami cedera/jatuh, pasien telah menjaga kebersihan tempat tidurnya dan pusing pasien sudah berkurang. Pada tanggal 13 Juni 2019 masalah telah teratasi dengan hasil : pasien tidak ada cedera, pasien mulai beraktivitas, pasien sudah tidak ada rasa cemas dan takut jatuh.

Untuk diagnosa yang kedua maka dapat didapatkan hasil evaluasinya adalah : pada tanggal 11 Juni 2019 masalah belum tertasi karena pasien nampak lemah, pasien belum menggunakan masker dirumah sakit dan pada saat kontak dengan orang lain. Pada tanggal 12 Juni 2019 masalah belum teratasi karena pasien sudah menunjukkan telah memakai masker pada saat dirumah sakit dan pasien nampak membersihkan lingkungannya. Pada tanggal 13 Juni 2019 masalah telah teratasi dengan hasil : pasien nampak memakai masker pada saat dirumah sakit dan akan menggunakannya pula pada saat dirumah, lingkungan pasien nampak bersih dan pasien dapat membatasi pengunjung untuk menghindari terjadinya penyebaran infeksi.

Diagnosa ketiga maka didapatkan hasil evaluasinya adalah : pada tanggal 11 Juni 2019 masalah belum teratasi disebabkan oleh pasien belum menggunakan masker pada saat kontak dengan orang lain, pasien belum menutup mulut pada saat batuk, pasien mengalami tekanan darah tinggi. Pada tanggal 12 Juni 2019 masalah belum teratasi karena pasien mulai menggunakan masker pada saat kontak dengan orang lain, pasien telah menutup mulut pada saat batuk tetapi tekanan darah klien masih tinggi dengan hasil TD : 160/70 mmhg, nadi : $88 x / i$, suhu : $36,5^{\circ} \mathrm{C}$ dan pernapasan : $24 x / i$. Pada tanggal 13 Juni 2019 masalah belum teratasi yang disebabkan oleh tekanan darah masih tinggi dengan hasil TD : 160/80 mmhg, nadi : 86x/i, suhu : $36,5^{\circ} \mathrm{C}$ dan pernapasan : 22x/i. Pada tanggal 14 Juni 2019 maslah telah teratasi dengan hasil : tandatanda vital, TD : 130/40 mmhg, nadi : 88x/i, suhu : $36,5^{\circ} \mathrm{C}$ dan pernapasan :24x/i. Hasil TTV yang dituliskan pada diagnosa ini langsung pada hasil akhirnya karena pasien dipantau tiap 4 jam.

\section{KESIMPULAN DAN SARAN \\ Kesimpulan}

Berdasarkan data yang di peroleh dapat di simpulkan sebagai berikut :

1. Hasil pengkajian pada klien didapatkan klien mengalami anemia dengan nilai hemoglobin 5,9 g/dl dan PLT : $515 \times 10^{3}$, klien pusing pada saat beraktivitas, penglihatan klien berkunangkunang pada saat bangun dari tempat tidur, penglihatan klien kabur, klien kesulitan berjalan denagn sendiri, klien mengalami kelemahan, cemas dan juga adanya rasa takut untuk jatuh. Pemeriksaan penunjang yaitu foto thorax hasil TB paru lama nonaktif. Dari pemeriksaan pada Tn. S didapatkan keadaan umum lemah dengan TD: 160/90 mmHg, Nadi: $88 \mathrm{x} / \mathrm{menit}$, Suhu: $36,5^{\circ} \mathrm{C}$, Pernafasan: $24 \mathrm{x} /$ menit,

2. Diagnosa keperawatan yang muncul pada klien adalah :

a. Resiko cedera/jatuh berhubungan dengan kelemahan,

b. Resiko penyebaran infeksi berhubungan dengan penurunan system imun, aspek kronis penyakit

c. Perubahan proteksi berhubungan defisit imunologi.

3. Perencanaan keperawatan yang di lakukan penulis adalah :

a. Resiko cedera berhubungan dengan kelemahan. Kaji dan identifikasi faktor risiko cedera yang mungkin terjadi pada pasien, Identifikasi kemampuan pasien untuk berjalan, berpindah, dan aktivitas, Kaji kemampuan pasien dalam menggunakan alat bantu jalan seperti kruk, tripot, dan lain-lain, Jaga kebersihan lantai kamar, Gunakan alas kaki pasien yang tidak licin dengan hak rendah, Jaga kebersihan tempat tidur, laken bersih dan kencang, Tempatkan barang-barang berbahaya ditempat yang aman, Bantu pasien dalam melakukan aktivitas dan mobilisasi, 
Lakukan perubahan posisi setiap 2 jam pada pasien tirah baring, Berikan pendidikan kesehatan pada keluarga tentang risiko cedera pada jatuh.

b. Resiko penyebaran infeksi berhubungan dengan penurunan system imun, aspek kronis penyakit, Bersihkan lingkungan setelah dipakai pasien lain, Batasi pengunjung bila perlu, Instruksikan pada pengunjung untuk mencuci tangan saat berkunjung dan setelah berkunjung meninggalkan pasien, Gunakan sabun antimikrobia untuk cuci tangan, Cuci tangan setiap sebelum dan sesudah makan.

c. Perubahan proteksi berhubungan defisit imunologi, Kaji kembali risiko pasien yang terjadi infeksi nasokomial, Kaji status nutrisi pasien, Observasi tanda vital, tekanan darah, suhu, nadi dan pernapasan setiap 4 jam, Kaji hasil laboratorium seperti $\mathrm{Hb}$, Gunakan perlindungan khusus, seperti penggunaan masker, sarung tangan jika kontak dengan orang lain, Jaga kebersihan diri pasien, Penatalaksanaan dengan tim medis dalam pemberian obat untuk meningkatkan daya tahan tubuh, Anjurkan pasien untuk meningkatkan tidur yang cukup, Anjurkan pasien untuk menghindari keadaan stres .

4. Implementasi yang di lakukan sesuai dengan rencana keperawatan atau intervensi keperawatan sesuai dengan kondisi pasien.
5. Evaluasi Keperawatan,

a. Pada diagnosa pertama masalah teratasi

b. Pada diagnosa kedua masalah teratasi

c. Pada diagnosa ketiga masalah teratasi

\section{Saran}

Adapun saran yang dapat di berikan oleh penulis sebagai bahan evaluasi sebagai berikut :

1. Saran bagi perawat yang dimana, perawat rumah sakit seharusnya memberikan edukasi atau pemahaman kepada keluarga pasien tentang mudahnya menular penyakit tuberkolosis tersebut, dan meberikan pemahaman tentang bagaimana mencegah agar tidak terjadi penularan ke anggota keluarga lainnya.

2. Dalam merumuskan diagnosa keperawatan, harus sesuai dengan data yang di temukan pada saat melakukan pengkajian.

3. Dalam menyusun perencanaan keperawatan, sangat perlu di perhatikan masalah utama yang di alami pasien agar masalah tersebut dapat teratasi sesuai yang di harapkan.

4. Dalam melakukan tindakan keperawatan harus di lakukan sesuai dengan intervensi yang telah di susun.

5. Dalam melakukan evaluasi harus sesuai dengan kriteria hasil dari intervensi dan implementasi yang telah di berikan.

\section{DAFTAR PUSTAKA}

Abd wahid-Iman suprapto. (2013). Asuhan Keperawatan Pada Gangguan Sistem Respirasi. jakarta timur: Trans Info Medika.

Abdullah. (2014). Kebutuhan Dasar Manusia. Jakarta Timur: CV. Trans Info Media.

Afrianti, T. (2014). Metodologi Penelitian Kualitatif dalam Riset Keperawatan. Jakarta: PT Rajagrafindo Persada.

Bararah, T., \& Jauhar, M. (2013). Asuhan Keperawatan : Panduan Lengkap Menjadi Perawat Profesional Jilid 1. Jakarta: Prestasi Pustaka Raya.

Doenges, M. E. (2014). Rencana Asuhan Keperawatan . Malang: EGC.

Junaidi, I. (2010). Penyakit Paru dan Saluran Napas. Jakarta: PT Bhuana IImu Populer.

Manurung, S., Suratun, Krisanty, P., \& Ekarini, N. L. (2013). Gangguan Sistem Pernapasan Akibat Infeksi. Jakata: Trans Info Media.

Nizar, M. (2017). Pemberantasan dan Penanggulangan Tuberkulosis. Yogyakarta: Gosyen Publishing.

nugroho, t. (2011). Asuhan Keperawatan. Yogyakarta: Nuha Medika.

Nurarif, A. H., \& Kusuma, H. (2015). Aplikasi Asuhan Keperawatan Berdasarkan Diagnosa Medis dan Nanda NicNoc Jilid 3. Jogjakarta: Mediaction.

Rab, P. D. (2010). Ilmu Penyakit Paru. Jakarta: Trans Info Media. 
Jurnal Media Keperawatan: Politeknik Kesehatan Makassar

Vol. 10 No. 022019

e-issn : 2622-0148, p-issn : 2087-0035

Rab, T. (2016). IImu Penyakit Paru. Jakarta: Trans Info Media.

Rahardjo. (2017). Studi Kasus dalam Penelitian Kualitatif Konsep . Jakarta: CV. Trans Media.

Roshdahl, C. B. (2014). Buku Ajar Keperawatan Dasar. jakarta: EGC.

Smeltzer, S. C. (2012).

Suprapto, A. W. (2012). Dokumentasi Proses Keperawatan. Yogyakarta: Nuha Medika.

Wartonah, T. \&. (2015). Kebutuhan Dasar Manusia dan Proses Keperawatan. Jakarta: Salemba Medica.

Wijaya, A. S., \& Putri, Y. M. (2013). Keperawatan Medikal Bedah 1. yogyakarta: nuha medika.

Sheba Denisica Nasution, (2015). Malnutrisi dan Anemia Pada Penderita Tuberkulosis Paru. Diakses dari juke.kedokteran.unila.ac.id. Pada tanggal 08 Maret 2019.

Emma Novita \& Zata Ismah (2017). Studi Karakteristik Pasien Tuberkulosis di Puskesmas Seberang Ulu 1 Palembang. Diakses dari http://journal.unnes.ac.id. Pada tanggal 08 Maret 2019.

Ibrahim, A. S., (2012). Panik Neurologis dan Gangguan Cemas. Tangerang. Jelajah Nusa.

Wahyuni, Indarwati, Aris Sugiarto. (2015). Kajian Persepsi, Pengetahuan Terhadap Pencegahan Penularan Penyakit TB di Puskesmas. Diakses dari http://ejournal.stikespku.ac.id. Pada tanggal 08 Maret 2019.

Hafizhatun Nadia. (2018). Analis Resiko Keselamatan dan Kesehatan Kerja Pada Petugas Kebersihan di Rumah Sakit. Diakses dari https://journal.Ippm-stikesfa.ac.id. Pada tanggal 08 Maret 2019.

Irandi Putra Pratomo. (2012). Malnutrisi dan Tuberkulosis. Jakarta. Artikel Pengembangan Pendidikan Keprofesian Berkelanjutan (P2KB). 